Journal of Bangladesh Academy of Sciences, Vol. 38, No. 1, 1-6, 2014

\title{
INTERNAL DEFECTS AND WATER ABSORPTION BEHAVIOR OF ENVIRONMENTALLY FRIENDLY BRICK-MAB USING FILM NEUTRON RADIOGRAPHY TECHNIQUE
}

\author{
M. K. ALAM*, M. R. ISLAM ${ }^{1}$, S. SAHA, M.N. ISLAM AND S. M. AZAHARUL \\ ISLAM $^{1}$ \\ Reactor and Neutron Physics Division, Institute of Nuclear Science and Technology, \\ AERE, Savar, Dhaka, Bangladesh
}

\begin{abstract}
Film neutron radiography (NR) technique has been adopted to study the internal defects like homogeneity, porosity, incremental intrusion area, initial rapid absorption (IRA) and water penetrating height/behavior of the automated machine made environmentally friendly brick-MAB sample. Thermal neutron radiography facility installed at the tangential beam port of 3 MW TRIGA MARK-II reactor was used in this study. In here optical density or gray values of the neutron radiographic images of the sample was measured. From the measurement it was found that most of the areas of this sample were homogeneous, which indicateed the presence of a little bit internal porosity and absorption of water to be very poor. It also showed that its initial rapid absorption was less and water absorption behavior was capillary and of wave shape.
\end{abstract}

Key words: Neutron radiography, Homogeneity, Water absorption behavior

\section{INTRODUCTION}

Neutron radiography is a powerful non-destructive testing (NDT) technique for detection of internal defects such as, voids/cavity, cracks, homogeneity (Alam and Khan 2006), porosity etc. of materials. It is also a technique of making a picture of the internal details of an object by the selective absorption of a neutron beam by the object. Neutron radiography (NR) is used for the basic principles of radiography whereby a beam of radiation is modified by an object in its path and the emergent beam is recorded on a photo film (detector). In general, the radiography technique is a simple process of exposing objects to an X-ray, gamma-ray, neutron beam and other types of radiation and then attenuated outgoing beam from the object passed through a special type of photographic film to form images of the objects on the radiographic film or detector. The NR facility described by Ahsan et al. (1995) and Islam et al. (1995) was used for characterizing the internal structure, internal defects in materials like ceramics, tiles (Alam et al. 2007) and different building materials (Islam et al. 2000). Clay is a widely available raw material that survives very well in its fired form. Clay bricks have been

\footnotetext{
* Corresponding author: <alammk1964@yahoo.co.in>.

${ }^{1}$ Department of Physics, Jahangirnagar University, Savar, Dhaka, Bangladesh.
} 
found in the ruins of ancient civilizations Maithel et al. (2012). Bhatnagar and Goel (2002) saw that properties of these bricks are affected as a result of physical, chemical and mineralogical changes (Bhatnagar and Goel 2002), Cultrone et al. 2004). Mbumbia et al. (2000) stated that compressive strength and water absorption are two major physical properties of brick that are good predictors of bricks ability to resist cracking of face. Water absorption is a measure of available pore space and is expressed as a percentage of the dry brick weight. It is affected by properties of clay, method of manufacturing and degree of firing. Water absorption capacity of the brick affects the surface finishing of the brick-laid wall (Presertsan and Theppaya 1995, 1986, Marrusin 1985). Any inhomogeneity in the object of an internal defect like voids, cracks, porosity, inclusion, corrosion etc. will show up as change in gray value/radiation intensity reaching the detector. The objectives of the present work was to determine optimization of irradiation/exposure time, homogeneity, incremental intrusion area of water/water penetrating height and penetrating shape/behavior of the environmentally friendly brickMAB sample.

\section{MATERIALS AND METHODS}

The brick-MAB was collected from Millers automatic bricks factory, Shambhugonj, Mymensingh. After collection it was prepared/ polished at its actual size $23.464 \times 11.026$ $\times 6.416 \mathrm{~cm}^{3}$, for the experiment.

A thin converter (gadolinium metal foil of $25 \mu \mathrm{m}$ thickness) and the X-ray industrial film (Agfa structurix $\mathrm{D}_{4} \mathrm{DW}$ ) was loaded into the NR cassette at close contact in the darkroom.

The sample was placed in close contact with the NR cassette in front of the neutron beam (diameter $30 \mathrm{~cm}$ ), on the sample holder table.

The optimum exposure time of the dry sample was determined by taking a series of experiments/neutron radiographs with different exposure time, while the reactor was operated at constant power $250 \mathrm{~kW}$. For the present experiment the optimum exposure time was found 60 minutes. Exposure time differed for different samples, depending on the intensity of the neutron beam, neutron cross-section, density and thickness of the sample.

The sample was placed perpendicularly in a plastic pan and a constant $2.0 \mathrm{~cm}$ height of water level was maintained. The water level was observed very carefully and added extra water to maintain water level during the immersion time. After immersion, extra water of out side the sample was removed manually by tissue paper. 


\section{MATHEMATICAL FORMULATION}

Homogeneity/or internal defects e.g. voids, cracks, porosity/homogeneity or inclusion show up as a change in optical density and gray value/radiation intensity reaching the detector. Irradiation intensity varied after passing through the object under examination. The optical density and intensity/gray value variation obeyed the following general attenuation law of Norris et al. (1996) applicable for X-rays, gamma rays or neutrons:

$$
\mathrm{I}=\mathrm{I}_{0} \mathrm{e}^{-\mu \mathrm{x}}
$$

where,

$$
\begin{aligned}
& \mathrm{I}_{0}=\text { Intensity of the incident neutron beam. } \\
& \mathrm{I}=\text { Intensity of the emergent beam from the object. } \\
& \mu=\text { Neutron attenuation coefficient. } \\
& \mathrm{x}=\text { Thickness of the test object. }
\end{aligned}
$$

The attenuated neutrons beam entered the detector that resisted the fraction of initial radiation intensity that and was transmitted at each point in the object and was recorded in the radiographic film i.e. image detector.

Optical density of the imaging film was measured by image processing soft ware. Actually, optical density is the darkness or opaqueness of a transparency film and is produced by film exposure and chemical processing. An image contains areas with different densities that are viewed as various shades of gray. The relationship between the intensity spread at the pixel level and the overall appearance of an image provides the basis for image enhancement by gray-level transformation. The terms gray value and intensity are used synonymously to describe pixel brightness.

\section{RESULTS AND DISCUSSION}

The specific relationship between the shades of gray or density and exposure depends on the characteristics of the film emulsion and the processing conditions. Fig. 1(a-d) shows the radiographic images of the MAB sample at different immersion time for showing the actual immersion part and the incremental water intrusion zone. From the measurement of the gray value it was observed that a large portion of the sample was homogeneous i.e., the contents of the sample uniformly mixed and a little bit of pores existed in the sample. Fig. 2 shows that water penetrating height increased with increasing immersion time through the middle part and different edges. The actual penetrating height at the middle was 3.5, 4.2, 5.6 and $6.6 \mathrm{~cm}$, for 5, 10, 15 and 20 minutes immersion in water, respectively. In that case, rate of water rising through the middle 
increased gradually and through the edges it was a little bit higher than in the middle. These graphs show that the shape of the water rising through the sample is capillary and of wave shape. The IRA measurement shows that first 5 minutes water in absorption, is high. After that the rate of water absorption is very slow compare to first 5 minutes. The calculation of the optical density shows that water absorption behavior and incremental water intrusion area at different immersion time is slightly greater from one end to another (Figs 1, 2). Actually water absorption decreased significantly when the temperature increased due to the formation of the amorphous phase at high firing temperature. During the manufacturing time if the clay mixture absorbs more water, brick exhibits a larger pore size, resulting in a lower density (Karaman et al. 2006).
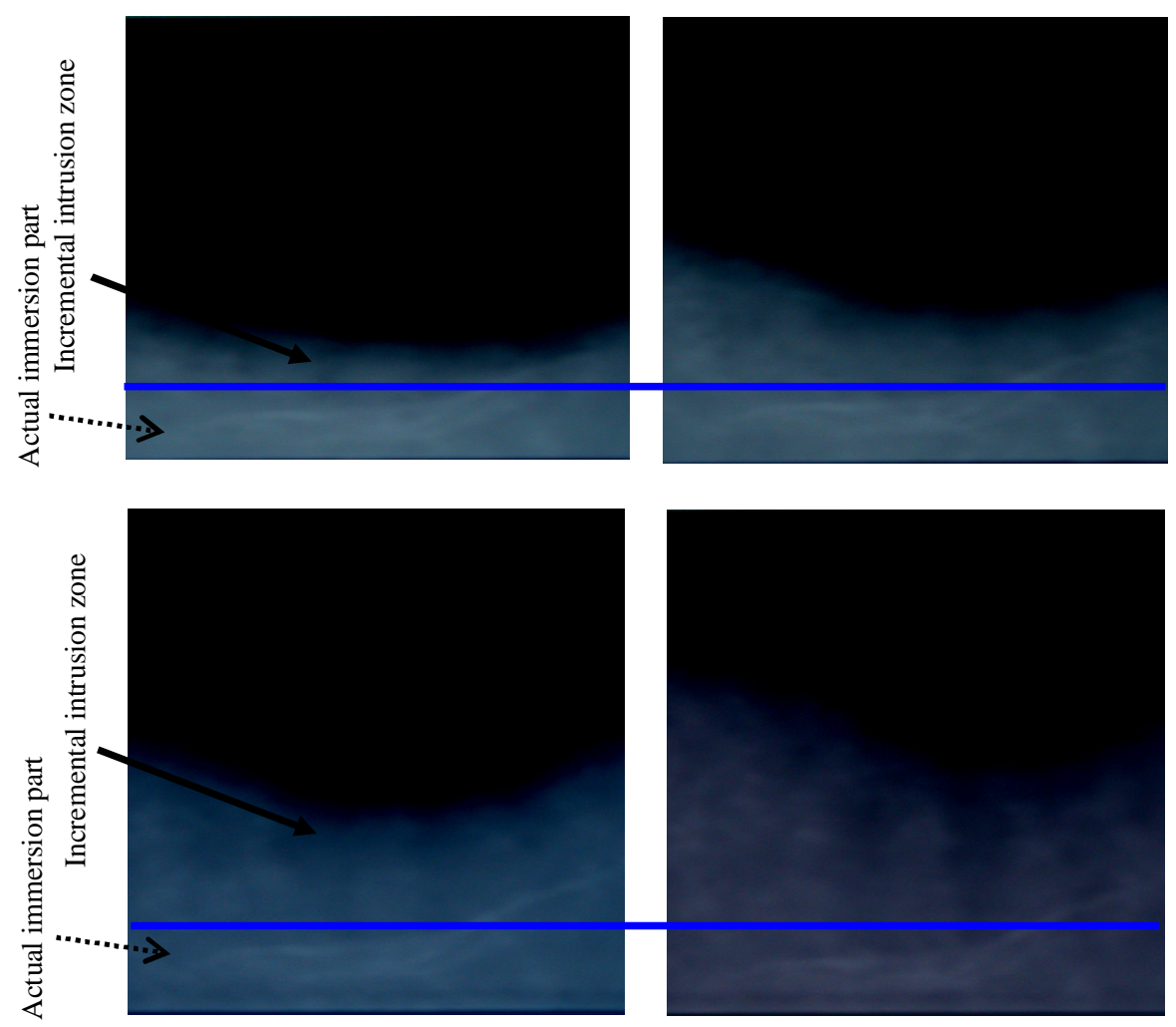

Fig. 1. Radiographic image of the brick-MAB sample at different immersion time : (a) 5 minutes, (b) 10 minutes, (c) 15 minutes and (d) 20 minutes indicating the water incremental intrusion zone and actual immersion part.

Depending on the water absorption time of brick, differences can be observed in capillary absorption (Weng et al. 2003). The present investigation showed that the water rising/penetrating behavior at different immersion time of the brick samples was capillary 
and wavy. Many authors (TS 704. 1979 and TS 705. 1975) studied that water absorption depends on submersion time, firing temperature and firing time. High values of water absorption indicated that the clay bricks produced were highly porous. Internal structure of the brick is expected to be intensive enough to avoid intrusion of water Weng et al. 2003).

Water penetrating/rising behavior of MAB

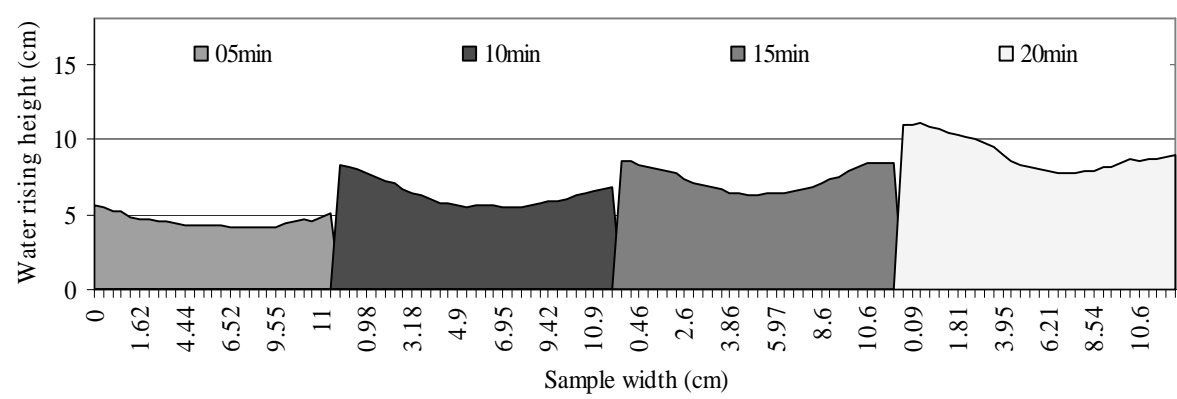

Fig. 2. Water rising/penetrating behavior of the $M A B$ sample at different immersion times.

Sanders and Frederic (2011) found a relationship between capillarity and freeze thaw durability. They stated that durability is a function of the pore structure and the nature of the fired bond. On the other hand, capillary absorption measures how well water moves through the brick, then it must have some bearing on the efflorescence potential. Theoretically, the rate of capillary absorption influences the bond between brick and mortar (mixture of lime, water and sand). Some authors did not believe that there was a direct relationship between IRA and performance and did not feel that IRA should be included in ASTM specifications. This disagreement is probably related to the lack of information contained in the IRA measurement. Workmanship plays a role in the quality of masonry that it is hard to definitively identify the influence of other factors. Rising damp and moisture transfer through masonry. A particular type of brick shows that the connectivity and orientation of pores also play a large part in the movement of water in the pores (Sanders and Frederic 2011). In the present investigation it was observed that the automated machine made environmentally friendly brick-MAB sample is better in quality. But it is essential to further improve the quality of this bricks by eliminating pores and better homogeneity to increase its longevity/stability.

\section{ACKNOWLEDGEMENTS}

Authors would like to thank the production Manager, Millers Automatic Bricks Factory, Mymensingh, for supplying the brick samples and to the Ministry of Science \& Technology for financial support in order to complete the research work. 


\section{REFERENCES}

Ahsan, M. H., M. N. Islam and M. K. Alam. 1995. Proc. of the 2nd International Topical Meeting on Neutron radiography system Design and Characterization. Rikkyo University, Japan, Nov. 12-18. pp. 30.

Alam, M. K. and M. A. Khan. 2006. Study of water absorption and internal defects in jute reinforced biopol composite using digital neutron radiography technique. J. Bangladesh Acad. Sci. $30: 29$.

Alam, M. K., M. N. Islam and M. A. Zaman. 2007. Study of internal defects and water absorption behavior of single layer Italian tiles using neutron radiography facility of 3 MW TRIGA MARK II research reactor. J. Bangladesh Acad. Sci. 31(2) : 213.

Bhatnagar, J. M. and R. K. Goel. 2002. Thermal changes in clay products from alluvial deposits of the Indo-Gangetic plains. Const. Build. Mate. pp. 113-122.

Cultrone, G., E. K. Sebastian,. M. J. Elert, Torre, O. Cazalla and C. R. Vavarro. 2004. Influence of mineralogy and firing temperature on the porosity of bricks. J. Euro. Ceramic Soc. 13 : 621-634.

Islam, M. N., M. M. Rahman, M. H. Ahsan., A. S. Mollah, Ahsan M. M. and M. A. Zaman 1995. Jahangirnagar University Journal of Sci. 19 : 181.

Islam, M. N., M. K. Alam, M. A. Zaman, M. H. Ahsan and N. I. Molla. 2000. Application of neutron radiography to building industries. Ind. J. Pure and Applied Phys. $38: 348$.

Islam, M. N., M. M. Rahman, S. M. A. Islam and M. A. Zaman. 2000. Neutron radiographic investigation of the quality of some rubber samples. Ind. J. Pure and Applied Phys. $38: 675$.

Karaman, S., S. Ersahin and H. Gunal. 2006. Firing temperature and firing time influence on mechanical and physical properties of clay bricks. Journal of Scientific \& Industrial research. 65 : 153-159.

Maithel, S., D. Lalchandani, G. Malhotra, P. Bhanware, R.Uma, S. Ragavan, V. Athalye, K. R. Bindiya., S. Reddy, T. Bond, C. Weyant, E. Baum, V. T. K. Thoa., N. T. Phuong and T. C. K. Thanh. 2012. A Roadmap for Cleaner Brick Production on in India, Shakti Sustainable Energy Foundation and Climate Works Foundation Supported Initiative, April 2012.

Marrusin, S. L. 1985. Interrior fissures and microstructure of shale brick (Turkish Standards Institutions, Ankara, 1979). Am Ceramic Soc. Bull. 64 : 674-678..

Mbumbia, L., A. M. Wilmars and J. Tirlocq. 2000. Performance characteristics of lateritic soil bricks fired at low temperatures: A case study of Cameroon. Const. Build. Mat. 14 : 121-131.

Norris, P. M., J. S. Brenizer, D. A. Paine and D. A. Bostain. 1996. Measurements of water deposition in aerogel by neutron radiography. Proc. $5^{\text {th }}$ World Conf. on Neutron Radiography, Berlin, Germany, June 17-20. pp. 602.

Presertsan, S. and T. Theppaya. 1995. A study towards energy saving in brick making. Part 1: Key parameters for energy saving. RERIC Int. Energy J. 17 : 145-156.

Sanders, J. and J. Frederic. 2011. The national brick research center, 2011 structural clay products division meeting.

TS 704. 1979. Clay bricks (wall tile). Turkish Standards Institution, Ankara.

TS 705. 1975. Solid bricks and vertically perforated bricks. Turkish standards institution, Ankara.

Weng, C. H., D. F. Lin and P. C. Chiang. 2003. Utilization of sludge as brick materials. $A d v$. Environ. Res. 7 : 679-685. 